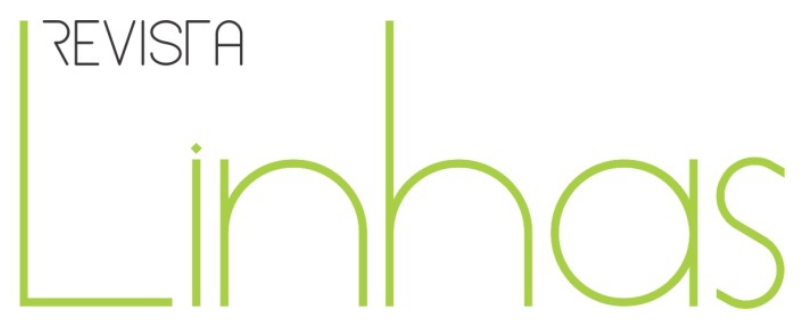

\title{
Retorno sobre Os herdeiros de Pierre Bourdieu e Jean-Claude Passeron ${ }^{1}$
}

\section{Resumo}

Os herdeiros de Pierre Bourdieu e Jean-Claude Passeron se tornou um "clássico" da sociologia francesa da educação. Este artigo apresenta o lugar desta obra na sociologia da educação renascente no início dos anos 1960, momento em que grande parte dos trabalhos tratava da democratização do ensino. Nele são analisados os modos de coleta e de tratamento dos dados adotados pelos autores de Os herdeiros. Se o modo de coleta dos dados parece muito artesanal, o modo de tratamento dos mesmos apresenta uma certa inovação em relação às pesquisas anteriores. Os herdeiros revela, finalmente, alguns dos traços da história da sociologia francesa nos anos sessenta.

Palavras-chave: Os Herdeiros; Pierre Bourdieu e Jean-Claude Passeron; Sociologia da Educação; 1960.

\section{Philippe Masson}

Doutor em Sociologia pela École des Hautes Études en Sciences Sociales - EHESS - Paris/França philippe.masson@univ-nantes.fr

\footnotetext{
Para citar este artigo:

MASSON, Philippe. Retorno sobre Os herdeiros de Pierre Bourdieu e Jean-Claude Passeron. Revista Linhas. Florianópolis, v. 15, n. 29, p. 92-111, jul./dez. 2014. Título original: Retour sur Les Héritiers de Pierre Bourdieu et Jean-Claude Passeron. Traduzido por Ione Ribeiro Valle, com revisão técnica de Ione Ribeiro Valle.
}

DOI: $10.5965 / 1984723815292014092$

http://dx.doi.org/10.5965/1984723815292014092

\footnotetext{
${ }^{1}$ Traduzido por Ione Ribeiro Valle - ione.valle@ufsc.br.
} 


\title{
Back to The Inheritors of Pierre Bourdieu and Jean-Claude Passeron
}

\begin{abstract}
Les Héritiers by Pierre Bourdieu et Jean-Claude Passeron has become a classic in French education sociology. This article presents the position of the book in the revived education sociology at the beginning of the 1960s, where a large part of the work focused on the democratization of education. The article analyses too the way data was gathered and processed by the authors of Les Héritiers. If the collection method appears to be very traditional, the processing method introduces some innovation in comparison to previous research. Finally, Les Héritiers presents certain characteristics of the history of French sociology in the 1960 s.
\end{abstract}

Keywords: The Inheritors; Pierre Bourdieu and JeanClaude Passeron; Sociology of Education; 1960. 


\section{Introdução}

O livro de Pierre Bourdieu e Jean-Claude Passeron, Os Herdeiros, se tornou um clássico da sociologia francesa ${ }^{2}$. Dele foram vendidos mais de 100.000 exemplares, sendo bastante conhecido fora do círculo relativamente estreito dos sociólogos. Ele teve uma forte influência tanto na sociologia francesa como na política escolar daquele país e, de maneira mais ampla, nas concepções que temos hoje sobre a escola. Os manuais que apresentam um panorama da sociologia da educação, ou mesmo do conjunto da sociologia francesa, evocam com frequência esta obra para caracterizar o ponto de vista de seus autores sobre a instituição escolar ou para delinear a história desta especialidade depois da Segunda Guerra Mundial. Os Herdeiros se tornou uma referência obrigatória para aqueles que desejam analisar, a partir de um ponto de vista sociológico, os estudantes. Ele é algumas vezes considerado, assim como outros trabalhos de Pierre Bourdieu - como A distinção, que evocarei mais adiante - como emblemático de uma escola sociológica. Em suma, ele é um bom exemplo de relatório de pesquisas empíricas da sociologia francesa ocupando um lugar importante na sua história.

A obra de Bourdieu e Passeron foi lançada em 1964, num período de crescimento da escolarização francesa nos níveis secundário e superior, seguido de muitos debates sobre a democratização. A formação de uma mão de obra qualificada quantitativamente suficiente em relação às necessidades da economia aparece como necessária aos planejadores e aos homens políticos no poder. Não é mais aceitável que o acesso às posições profissionais qualificadas seja reservado a uma pequena fração da população beneficiada por uma origem social privilegiada. Desde então, com a chegada de numerosas faixas etárias no ensino secundário e com a aplicação de reformas que favoreciam o prosseguimento dos estudos, os administradores da Educação Nacional esperavam uma democratização do ensino. Tratava-se, na verdade, de "incorporar as elites a partir de uma base democrática" ${ }^{3}$. Por outro lado, as transformações da Universidade francesa foram seguidas de mudanças significativas no sindicalismo estudantil. Os sindicatos estudantis haviam se posicionado vivamente contra a guerra da

\footnotetext{
${ }^{2}$ Este texto é uma tomada de um capítulo de um dos meus livros (MASSON, 2008) que apresenta a história da sociologia francesa após 1945 a partir de enquetes empíricas.

${ }^{3}$ Para retomar a expressão de Antoine Prost, na sua análise da política gaullista de educação (PROST, 1992, capítulo 5).
} 
Argélia. Com o fim desta, foi preciso encontrar novos temas para continuar mobilizando os estudantes e limitar a queda no número de alunos sindicalizados. Eles vão, portanto, centrar suas reivindicações na "condição estudantil". Um terceiro elemento do contexto remete às análises sociológicas em voga nos anos sessenta relativas ao desenvolvimento dos meios de comunicação de massa (o rádio, a televisão, o cinema). Sociólogos, como Edgar Morin (1962), pensam ver nesse desenvolvimento o surgimento de "uma cultura de massa". A obra de Bourdieu e Passeron apreende no contrapé essas análises que serão parcialmente postas em dúvida na segunda metade dos anos sessenta com a mudança de conjuntura política ${ }^{4}$. O contexto social e político, no momento da publicação da obra é, portanto, bastante favorável à sua difusão: debates públicos sobre a universidade, reivindicações estudantis e militantismo ativo dos estudantes. A obra vai ser utilizada pelas organizações sindicais de estudantes e pelos partidos políticos de esquerda, a partir do final dos anos sessenta, para justificar suas próprias análises da instituição escolar. Esses elementos contribuirão para a sua notoriedade, mas também para as interpretações posteriores do livro.

\section{Os autores}

Pierre Bourdieu, nascido em Denguin em 1930, filho de um carteiro que se tornou recebedor e distribuidor dos correios a Lasseube (próximo a Pau) nos Pirineus-Atlânticos, é originário da pequena burguesia. Após a conclusão do seu bacharelado ${ }^{5}$, ele ingressa, assim como Passeron, na École Normale Supérieure, onde prepara com sucesso sua agregação $^{6}$ de filosofia. Diferentemente dos sociólogos franceses da geração precedente, ambos se beneficiaram de uma sólida formação em filosofia que contribuiria, de maneira decisiva, para a orientação dos seus trabalhos futuros. Os anos cinquenta haviam sido marcados pela dominação nos debates intelectuais e filosóficos da fenomenologia e do existencialismo, cujo representante mais visível fora Jean-Paul Sartre. Sem dúvida, como ele frequentemente afirmou, Sartre se constituía para Pierre

\footnotetext{
${ }^{4}$ Para uma análise detalhada desse contexto, ver Masson, 2001. Sobre esse livro, ler-se-ão com interesse as contribuições reunidas em Chapoulie, Kourchid, Robert e Sohn (dir.), 2005, p. 13-119.

${ }^{5}$ Do original "baccalauréat", título de conclusão do liceu, correspondente ao Ensino Médio brasileiro. (N.T.)

${ }^{6}$ Do original "agrégation", título decorrente da aprovação em concurso público, indispensável para atuar como professor de liceu ou de faculdade. (N.T.)
} 
Bourdieu um modelo negativo na primeira parte de sua carreira universitária, rejeitando não somente a filosofia do sujeito e da consciência (um "humanismo") que ele propunha, mas também seu modelo de engajamento nos debates públicos. Paralelamente, uma história da filosofia (próxima de Martial Guéroult, Jean Hypolyte) e uma filosofia das ciências (Gaston Bachelard, Georges Canguilhem e Alexandre Koyré) se desenvolvia à margem dessa corrente dominante na filosofia francesa. Estes últimos vislumbravam a história do conhecimento científico como uma série cumulativa de modelos racionais livres de toda representação subjetiva. Esta filosofia das ciências vinha inspirando uma parte importante das análises das ciências sociais desde o final dos anos cinquenta. Ela marca um número importante de estudantes tanto do final dos anos cinquenta quanto dos anos sessenta que encontram nesses autores um novo modelo de cientificidade para as ciências sociais. A antropologia de Claude Lévi-Strauss representava, por outro lado, um modelo positivo. Este procurava extrair "a estrutura fundamental do espírito humano", tentando mostrar que toda representação do mundo põe em prática estruturas mentais inconscientes comuns a povos diferentes. A carreira de Lévi-Strauss (nascido em 1908), cuja legitimidade baseava-se no reconhecimento científico, eleito para o Collège de France em 1959 (um ano após a publicação do seu livro Antropologia Estrutural e quatro anos após o sucesso de Tristes Trópicos), poderia representar um modelo a ser seguido pela nova geração de pesquisadores em ciências sociais. É, aliás, nesta disciplina em moda que Bourdieu começa suas primeiras pesquisas na Argélia (BOURDIEU; DARBEL, 1963; BOURDIEU; SAYAD, 1964).

Jean-Claude Passeron, nascido em 1930 em Bouches-du-Rhône, filho de um professor primário, sucede Bourdieu em 1961 no posto de assistente de Raymond Aron na Sorbonne, após sua partida para a Faculdade de Lille. Sua colaboração com Bourdieu estende-se até 1972. Os primeiros trabalhos de Passeron, aqueles que realiza sozinho, referem-se à cultura: ele realiza uma enquete sobre o uso da fotografia entre o pessoal das fábricas Renault na década de 1960 (PASSERON, 1962)ㄱ. Após 1972, ele continua nesse domínio com pesquisas sobre a leitura, o uso da documentação audiovisual nas bibliotecas, os artistas (em colaboração com Raymonde Moulin), assim como com uma

\footnotetext{
${ }^{7}$ Esta primeira pesquisa de Passeron repousa sobre uma enquete por questionário e entrevistas junto a 44 membros do clube de fotos da empresa Renault. O autor não examina somente o equipamente e o uso do material fotográfico dos aderentes do clube, mas também a relação com diferentes gêneros fotográficos e as categorias de percepção e de julgamento nesse domínio. A conclusão propõe uma análise das funções sociais da imagem fotográfica.
} 
crítica da relação dos sociólogos (e de suas análises, particularmente aquelas de Bourdieu) com a cultura popular (GRIGNON; PASSERON, 1989). A defesa de uma tese de Estado na Universidade de Nantes em 1980 abre um novo período focado em trabalhos de epistemologia da sociologia que culminam, em particular, com a publicação de Raciocínio sociológico (PASSERON, 1991). Esta obra vai no contrapé daquela que ele havia assinado 20 anos antes com Bourdieu e Chamboredon (BOURDIEU; CHAMBOREDON; PASSERON, 1968).

\section{Os herdeiros: a iniciativa de novas enquetes de sociologia da educação}

Diz-se com frequência que é com Os herdeiros que os intelectuais e os políticos descobriram as desigualdades sociais na escola. É um exagero. Havia trabalhos nos anos de 1950 , realizados por pesquisadores do INED $^{8}$, sobre as desigualdades de orientação entre as diferentes áreas da instituição escolar. Mas elas eram remetidas a desigualdades de ordem econômica (as diferenças de renda). A força do livro de Bourdieu e Passeron consiste em propor uma tese simples e bem fundamentada empiricamente sobre essas desigualdades sociais e, ao mesmo tempo, se posicionar na contramão das teorias em voga na época. As desigualdades diante da escola não resultam somente da desigualdade dos recursos econômicos das famílias. Elas estão também na escola, elas se produzem durante todo o curso escolar e são explicadas essencialmente pelo pertencimento social, porque as classes sociais têm experiências diferenciadas do mundo. Os estudantes não formam um grande grupo social homogêneo? Não, se insurgem nossos dois sociólogos, pois as probabilidades de acesso ao ensino superior são muito diferentes segundo as classes sociais de origem dos estudantes. Além disso, sua relação com os estudos é radicalmente oposta e os originários das classes privilegiadas, os herdeiros que integraram há muito tempo as normas culturais da escola (que também são aquelas de seu meio social), podem se permitir uma relação falsamente distante, pois, apresentam todos os meios para serem bem sucedidos. Um ensino de massa no qual a orientação dos alunos, no final de um núcleo comum, dependeria de suas aptidões e de seus méritos não permitiria uma democratização da escola? Não muito, pois não há “dons escolares", a

\footnotetext{
${ }^{8}$ Instituto Nacional de Estudos Demográficos. (N.T.)
} 
escola não é libertadora. Ela contribui para a manutenção das desigualdades e, portanto, para a conservação da ordem social.

Os herdeiros mudou radicalmente a visão que na época se tinha da escola. Anteriormente, as análises (sociológicas ou não) sobre a instituição escolar manifestavam simpatia em relação à mesma. A partir do final dos anos sessenta, novas análises propõem uma imagem mais sombria desta instituição e insistem sobre suas funções de reprodução das desigualdades ${ }^{9}$. Isso significa que com Os herdeiros constitui-se progressivamente uma perspectiva autônoma das ciências sociais sobre a escola, fruto certamente da conjuntura da época, mas que mostra que as pesquisas empíricas podem apresentar inovações teóricas ou, mais precisamente, produzir um ponto de vista diverso daquele dos debates da época, ainda que parta deles. Os herdeiros também fornece um exemplo, entre outros, de uma obra cujo sucesso se deve, sobretudo, à maneira como foi interpretada e posteriormente utilizada, segundo contextos variados. Vale a pena lembrar aqui que Os herdeiros ignorava a dimensão temporal do fenômeno estudado. Os autores deixaram de lado toda análise diacrônica das respectivas partes das diferentes categorias socioprofissionais no ensino superior para concluir a rspeito da intangibilidade das desigualdades sociais diante da cultura. Eles não estavam interessados no grande crescimento dos matriculados no ensino superior. Mas, fundamentalmente, o sucesso público do livro e suas diversas utilizações tiveram como efeito estender o domínio de pertinência de Os herdeiros a uma base mais ampla do que aquela sobre a qual ele se referia inicialmente. Na verdade, a obra trata das desigualdades dos estudantes diante da cultura como, aliás, sugere seu subtítulo. Os dados empíricos do livro, como os do relatório com base no qual ele foi produzido, confirmam que se trata do sujeito tratado. No entanto, ao longo do tempo, a obra passou a ser utilizada como um livro que trata das desigualdades sociais no ensino e dos princípios por meio dos quais a instituição escolar favorece a manutenção dessas desigualdades. Várias enquetes sobre a cultura ou a escola dirigidas por Bourdieu e Passeron foram nesse mesmo sentido e outras enquetes dos mesmos autores sobre sujeitos próximos (a arte, a fotografia) também confirmavam a importância da classe social como fator decisivo para compreender as práticas nesses outros domínios.

\footnotetext{
${ }^{9}$ Eu examinei o quadro de recepção deste livro que contribuiu para esta inflexão em Masson (2005).
} 


\section{Cronologia das enquetes francesas sobre as desigualdades na escola entre 1950 e 1973}

As primeiras enquetes foram realizadas pelo Instituto Nacional dos Estudos Demográficos (INED) a partir de 1944 no quadro da Fundação para o estudo dos problemas humanos, mas os relatórios são bastante tardios.

1950: G. Heuyer; H. Pieron; A. Sauvy. Le niveau intellectuel des enfants d'âge scolaire. Une enquête national dans l'enseignement primaire, tome 1 , Cahiers $n^{\circ} 13$, INED.

1954: H. Bastide; H. Bergues; R. Gille; A. Girard; L. Henry; J. Sutter; L. Tabah. La détermination des aptitudes. L'influence des facteurs constitutionnels, familiaux et sociaux, tome 2 , Cahiers $n^{\circ} 23$, INED.

1952 a 1955: Vários artigos publicados na Revue Population, por A. Girard et al., sobre a orientação no final dos estudos primários.

1959: P. Naville (dir.). École et société, Paris: Librairie Rivière.

1963 a 1965: Enquete de Girard et al., sobre os alunos egressos do Curso Médio 2 ano. Vários artigos publicados na Revue Population.

1964: P. Bourdieu; J.-C. Passeron. Les Héritiers, Édition de Minuit (enquete iniciada em 1961).

1965: P. Bourdieu P.; Passeron J.-C.; Saint-Martin M. Rapport pédagogique et communication. Paris: Mouton.

1968: Número duplo da Revue française de sociologie, codirigida por P. Bourdieu e V. IsambertJamati.

1970: P. Bourdieu; J.-C. Passeron. La Reproduction. Paris: Édition de Minuit.

1970: A. Girard et al. Population et l'enseignement. Paris: Presses Universitaires de France. (Esta obra reúne os artigos publicados na Revue Population).

1971: C. Baudelot; R. Establet. L'école capitaliste en France. Paris: Maspéro.

1973: R. Boudon. L'inégalité des chances. Paris: Armand Colin.

A perspectiva de Bourdieu e Passeron se constituiria posteriormente num dos temas recorrentes da literatura sociológica sobre os estudantes. Na verdade, as obras francesas que aparecem em seguida, e que tomam como objeto os estudantes, vão geralmente se situar em relação a esta problemática. Assim, o livro Os estudantes, o emprego e a crise, publicado em 1981, por Christian Baudelot, Roger Benoliel, Hubert Cukrowicz e Roger Establet apresenta uma análise que se opõe (de maneira implícita) àquela desenvolvida em Os herdeiros. Os estudantes são apresentados como um grupo social homogêneo em razão das funções que os autores atribuem à Universidade. Esta produz os "pequenos-burgueses" encarregados de assegurar as funções de enquadramento que a sociedade necessita. Foi preciso esperar uma dezena de anos 
(1992) para que os estudantes se tornassem novamente objeto de enquete empírica por ocasião do grande crescimento das matrículas na Universidade. No entanto, a questão da homogeneidade ou não dos estudantes como um grupo social permaneceu, até muito recentemente, um fio condutor do conjunto das enquetes empíricas relacionadas a esta população.

Além desse tema de pesquisa, o livro de Bourdieu e Passeron é um ponto de referência para os trabalhos que se sucedem em sociologia da educação. O fato de que Os herdeiros seja muitas vezes associado à obra $A$ reprodução a partir de 1970 também contribuiu para a sua notoriedade, o primeiro livro aparecendo a posteriori como uma ilustração empírica das teses apresentadas no segundo. A sociologia da educação se torna assim, nos anos de 1960, uma especialidade importante da sociologia francesa, à qual se incorporam mais e mais enquetes empíricas. O objetivo principal, senão único, das pesquisas é avaliar o papel da escola na construção das desigualdades sociais e apreender a relação entre a escola e as classes sociais. A questão é, portanto, a da ligação entre a formação escolar e as posições sociais adquiridas posteriormente (após o acesso aos postos de trabalho). Um tema que permanece dominante até o início dos anos 1980. Os sociólogos franceses mantêm até hoje um interesse pelas desigualdades escolares, o fio vermelho de toda a sociologia da educação. A lealdade aos valores do ideal republicano (igualdade) e os debates recorrentes a eles associados tornam este domínio da sociologia inevitavelmente ligado, sob formas variadas, a esta questão política que é a desigualdade das oportunidades. Se a análise das desigualdades permanece central na sociologia francesa dos anos 1990-2000, o desenvolvimento das pesquisas etnográficas levaria a um deslocamento da perspectiva. A construção das desigualdades no interior da escola se torna um objeto frequente de pesquisas.

A posição extrema, ou atribuída como tal (pois o ponto de vista de Bourdieu e Passeron sobre a escola é mais complexo que a vulgata que progressivamente se impôs a partir do título de seu livro de 1970, A reprodução) ${ }^{10}$, de suas análises é uma das razões da notoriedade destas. Na verdade, Os herdeiros e A reprodução reúnem críticas de todas as análises sobre a Universidade em voga na França nos anos sessenta. Sendo assim, a interpretação tecnocrática mais próxima do ponto de vista governamental é criticada. A

\footnotetext{
${ }^{10}$ No que concerne a Bourdieu, ver, por exemplo, Bourdieu (1997) e em relação a Passeron, ver seu próprio exame crítico desta tese (Passeron, 1986; Fornel; Passeron, 2002).
} 
aplicação à Universidade feita por Michel Crozier de sua análise sobre o fenômeno burocrático também é visada explicitamente. Há até mesmo perspectivas freudianoesquerdistas e análises marxistas rápidas e simplistas que reduzem a Universidade a uma universidade de classes, mera engrenagem do capitalismo monopolista de Estado, ignorando assim a autonomia da instituição escolar posta em evidência por Bourdieu e Passeron. Por essa razão, as duas obras destes autores (nesse domínio) se tornaram pontos de referência ou referência para a constituição de novas análises alternativas. $\mathrm{Na}$ verdade, a obra de Baudelot e Establet, A escola capitalista na França (1971), de um lado, e a de Boudon, A desigualdade das oportunidades (1973), de outro, podem ser - e muitas vezes foram - lidas como análises alternativas. Os relatórios deste último livro e, posteriormente, muitos manuais de sociologia destinados aos estudantes construíram uma oposição binária entre Os herdeiros e A desigualdade de oportunidades ${ }^{11}$. Esta oposição binária foi utilizada, durante algum tempo, como um "meio de orientação" na profissão dos sociólogos, como também o é a noção "de escola” para qualificar uma tradição de pesquisa ou um conjunto de trabalhos de autores diversos situados sob uma mesma bandeira teórica.

\section{A inovação metodológica e redacional}

Ao se prender ao modo de coleta dos dados, o livro não se diferencia das monografias de sociologia do trabalho realizadas na segunda metade dos anos cinquenta. A documentação recolhida e apresentada baseia-se, sobretudo, em entrevistas e na exploração de questionários. A abordagem estatística aparece como o principal instrumento de prova. Onde reside, portanto, a inovação? Uma inovação técnica (ou metodológica) foi imediatamente percebida na época: trata-se das tabelas e gráficos (do capítulo 1 do livro Os herdeiros) que medem as chances objetivas de acesso (ou probabilidades de acesso) ao ensino superior segundo as diferentes categorias socioprofissionais. Trata-se de uma maneira surpreendente e objetiva de medir as desigualdades. Os filhos de profissionais liberais e de executivos de nível superior tinham

\footnotetext{
${ }^{11}$ Isso não significa que não existem diferenças reais entre Os herdeiros e A desigualdade de oportunidade sobre a questão das desigualdades sociais de escolarização. Uma das maiores diferenças reside no fato de que Raymond Boudon minimiza a importância da herança cultural na explicação dessas desigualdades e atribui, implicitamente, um lugar preponderante às desigualdades econômicas como fator determinante. Ele se reúne assim às explicações avançadas anteriormente nos trabalhos de Alain Girard.
} 
quase 42 vezes mais chances de ingressar na Universidade do que os filhos de trabalhadores $(58,5 / 1,4)$. O livro introduz também importantes inovações em termos de análise dos dados. Os relatórios de pesquisas sociológicas dos anos cinquenta conservam um caráter muito descritivo. As respostas dos entrevistados foram apreendidas como uma expressão fiel de seu julgamento ou de seu comportamento. Bourdieu manifestava uma clara hostilidade por essas pesquisas empíricas julgando-as "positivistas", destituídas a seu ver de ambição teórica. Em Os herdeiros, os extratos de entrevista são apresentados para ilustrar uma prática pelo seu conteúdo informativo imediato, ou para ilustrar um comportamento efetivo contrário às declarações. Para Bourdieu e Passeron, não há questões e respostas neutras e não se pode acreditar que um questionário garanta a univocidade das respostas. Não existem, portanto, dados imediatamente acessíveis, eles sempre são construídos pelo pesquisador.

Além disso, o livro repousa ao mesmo tempo sobre a filosofia das ciências que se desenvolvia na época (apoiando-se na ideia de que era preciso romper com o senso comum) e sobre o modelo da antropologia estrutural na busca de "leis gerais" dos comportamentos sociais. A determinação objetiva das "condições sociais de possibilidades" dos comportamentos (uma noção que encontra diretamente sua inspiração na filosofia de Kant, particularmente aquela expressa na Crítica da razão pura, que continuava uma referência) também contribui para definir um modelo de cientificidade para a sociologia. Os comportamentos sociais são na verdade determinados por elementos estruturais os quais os indivíduos não têm necessariamente consciência. A função da escola na sociedade (que é de reproduzir a ordem social) é apresentada como invariante, o que permite explicar as razões pelas quais as desigualdades escolares se perpetuam. Para Bourdieu e Passeron, trata-se, portanto, de estabelecer uma sociologia científica a partir do modelo das ciências da natureza e, mais especificamente, das ciências físicas. Sobre esses pontos, esse livro se opunha à filosofia existencialista (como a de Sartre) claramente dominante ao longo dos últimos quinze anos. Finalmente, Os herdeiros e o conjunto dos trabalhos realizados sob a direção de Bourdieu e Passeron renovavam em relação ao que a sociologia poderia propor: análises julgadas rigorosas e científicas (porque se apoiavam principalmente em instrumento estatístico), mas conceitualizadas (com muitos conceitos como o de ethos de classe, por exemplo; basta 
referir-se ao índex da obra) e que pretendiam analisar de maneira sutil os comportamentos.

\section{A influência difusa: as normas de uma nova definição da sociologia}

O papel de Os herdeiros na história da sociologia francesa não se reduz a este aspecto. A obra participou da redefinição de sociologia nos anos sessenta. Em primeiro lugar, Os herdeiros aparece como um modelo de relatório empírico que asssocia ao mesmo tempo - é esta combinação que é essencial - o uso de estatísticas obtidas por meio de fontes variadas (registros administrativos e enquetes por questionário), o que na época caracterizava uma enquete científica, a interpretação não positivista das respostas dos respondentes (ou seja, não apreender suas respostas em seu valor aparente) e o uso de categorias de análise abstratas. Os herdeiros aparecia, portanto, como um modelo de enquete empírica para as novas gerações de professores-pesquisadores e de pesquisadores que haviam iniciado sua carreira nos anos sessenta. Desse ponto de vista, Os herdeiros junta-se aos trabalhos anteriores de Pierre Bourdieu sobre a Argélia. Além disso, os trabalhos de Bourdieu sobre a Argélia, assim como aqueles sobre os estudantes ou a arte, utilizam amplamente o código das categorias socioprofissionais (CSP) como categoria de tratamento e de análise dos dados, atribuindo-lhes um papel determinante nas enquetes. Esses trabalhos vão exercer uma forte influência sobre a nova geração dos estatísticos do Instituto Nacional da Estatística e dos Estudos Econômicos (INSEE) que está na origem do código das Categorias socioprofissionais. Uma parte deles foi formada por Bourdieu e alguns colaboraram diretamente com as enquetes que ele dirigiu.

Em segundo lugar, a sociologia francesa dos anos cinquenta não repousava sobre a tríade dos fundadores (Marx, Durkheim, Weber) como a de hoje. As premissas da cultura da sociologia, tal como são apresentadas por Wallerstein, não estavam totalmente estabelecidas na França naquela época (WALLERSTEIN, 1999). Do que se trata? Com frequência apresenta-se a sociologia como uma disciplina dividida entre vários pólos, que se qualifica às vezes como escolas, como correntes diferentes. Esse modo de apresentação é comum e muito prático para o ensino. No entanto, ele mascara o que aproxima os sociólogos, o que forma uma comunidade profissional com suas revistas, 
seus departamentos universitários, seus laboratórios, seus objetos de pesquisa, etc. Além desses elementos institucionais indispensáveis que na prática fundam a homogeneidade da profissão, existe segundo Wallerstein, uma “cultura da sociologia”, um núcleo comum mínimo, um conjunto de premissas que deve ser simples para que possa ser compartilhado pelo maior número. Segundo Wallerstein, a primeira dessas premissas é originária da obra de Durkheim. Ela insiste sobre a realidade objetiva dos fatos sociais e pode ser resumida da seguinte maneira: "existem grupos sociais que têm estruturas explicáveis, racionais" (p. 165). Esse postulado está intimamente associado à ideia de que os fatos sociais devem ser tratados como coisas, para retomar a fórmula de Durkheim. Se esse primeiro postulado, que permite fundar a sociologia como ciência, foi partilhado por uma grande parte dos sociólogos franceses dos anos cinquenta, esta última formulação durkheimiana, originária das Regras do método sociológico, não havia sido retomada pelos sociólogos franceses. Raymond Aron tinha, por exemplo, uma opinião reservada e cética sobre a obra de Durkheim, inclusive sobre as Regras do método sociológico. A segunda premissa, extraída da obra de Marx, repousa sobre a perenidade do conflito social. A terceira, proveniente da obra de Weber, repousa sobre a existência de mecanismos de legitimação para conter esse conflito social. As noções de "legitimidade" e de “dominação legítima” são, evidentemente, essenciais aqui. Weber era muito ignorado, mas não desconhecido, antes dos anos sessenta, principalmente pelos sociólogos que realizaram enquetes empíricas.

As pesquisas empíricas realizadas pelos sociólogos franceses entre 1945 e o final dos anos cinquenta não repousam jamais sobre essas três premissas a um só tempo. Elas também não se apoiam sobre os esquemas gerais desenvolvidos por esses três "pais fundadores". Se considerar os fatos sociais como passíveis de objetivação não era incomum num período em que conhecer a realidade social era essencial, a ideia de centrar, por exemplo, as análises nos fenômenos sociais a partir da existência de mecanismos de dominação não era frequente. As obras de Weber não estavam disponíveis em francês naquela época, e Aron, um dos primeiros na França a apresentar o sociólogo alemão desde 1935, não havia efetivamente conquistado a adesão. A comparação com os Estados Unidos pode ser esclarecedora. Como sublinha Connell (1997) para a sociologia americana, considerar Durkheim, Marx e Weber os "três pais fundadores" da sociologia é relativamente recente. Foi durante os anos sessenta na 
França, e durante a década precedente nos Estados Unidos, que se vê aparecer esta organização da sociologia em torno dos "três pais fundadores". Ela corresponde à necessidade de uma definição específica desta disciplina no momento em que a mesma progressivamente se institucionaliza diante das disciplinas concorrentes num contexto de forte crescimento do número de estudantes. Uma pedagogia centrada na leitura dos textos canônicos desses três sociólogos também se desenvolve neste período. Entre as primeiras apresentações na França de uma definição da sociologia apoiada conjuntamente em Durkheim, Marx e Weber encontra-se a de Aron em seus cursos proferidos na Sorbonne nos anos 1960-1962, mas publicados em 1967. A obra de Aron, aliás, é a primeira a apresentar na França uma história da sociologia a partir da história das teorias dos autores do século XIX. No entanto, Aron também analisa outros autores além de Durkheim, Marx e Weber; ele evoca Montesquieu, Comte, Pareto e Tocqueville. Por que razões esses últimos não foram amplamente reutilizados na sequência em favor de uma focalização em torno de Durkheim, Marx e Weber? O contexto intelectual da disciplina é provavelmente uma das principais razões desta relativa colocação de lado. $\mathrm{Na}$ verdade, não surpreende o relativo desinteresse por Tocqueville num período marcado pelo estruturalismo e, a partir do final dos anos sessenta, por um certo retorno do marxismo, em particular, através das leituras de Althusser da obra de Marx. Tocqueville será com frequência apresentado como um dos "fundadores" da sociologia durante os anos 1970, e isso não de maneira sistemática. Pareto era percebido mais como um economista e Montesquieu como um filósofo político. Comte foi julgado representante do positivismo pouco útil para estudos empíricos.

É principalmente o contexto intelectual que define quais são os "pais fundadores" da disciplina e não uma definição a partir das obras dos que são qualificados como sociólogos anteriormente. A apresentação de Raymond Aron permanecia relativamente abstrata, ela não era suficiente para estabelecer a sociologia diante das outras disciplinas concorrentes. A sociologia precisava se apoiar em análises empíricas de objetos circunstanciados. Os herdeiros é o primeiro livro com base empírica na sociologia francesa que preenche esta função apoiando-se nos três fundadores (Durkheim, Marx e Weber) para analisar a instituição escolar. Considerando que as práticas estudantis assim como a relação com os estudos universitários podiam ser objetivados pela pesquisa sociológica, Bourdieu e Passeron procuraram mostrar que a instituição escolar tinha 
como consequência principal a legitimação das desigualdades culturais, mantendo assim os privilégios das categorias sociais mais favorecidas; em outras palavras, a permanência da ordem estabelecida. O que me parece essencial aqui não é a tese em si mesma, mas o fato de que a análise esteja fundada nos três axiomas evocados anteriormente e que seja possível encontrá-los na maior parte das análises sociológicas sobre a instituição escolar a partir dos anos 1960, quer elas adotem ou não a tese defendida por Bourdieu e Passeron. Em relação a seus antecessores, estes autores estão entre os primeiros a propor uma análise de um fenômeno social baseada não apenas numa abordagem mais abrangente das relações de classe (inspirando-se em Marx), mas também em alguns dos princípios de legitimação (Weber), os quais sustentariam, segundo eles, a ordem estabelecida e a estabilidade dessas relações, podendo ser objetivados por meio de dados quantitativos (Durkheim) ${ }^{12}$. A partir daí, eles fazem do estabelecimento de relações estáveis, próprias de uma determinada ordem de fenômenos, e da intenção de identificar uma ou algumas características essenciais desta ordem, um elemento central da definição da sociologia naquele período.

\section{A função de desvelamento das estruturas sociais}

Foi dito algumas vezes que Bourdieu havia mudado de ponto de vista em relação à questão do engajamento do sociólogo na Cidade na segunda metade do anos 1980. Ele começou a intervir com mais frequência nos debates públicos e na cena política quando na primeira parte de sua carreira havia manifestado um distanciamento maior. Na verdade, encontrar-se-á facilmente textos de Bourdieu que preconizam uma neutralidade axiológica necessária ao trabalho científico e entrevistas nas quais ele procura explicar essa mudança de atitude. Por outro lado, seus epígonos (particularmente os mais recentes) gostariam de sublinhar que a sociologia de Bourdieu sempre foi engajada, como ilustraria a coleção de suas intervenções qualificadas de políticas (BOURDIEU, 2002). Certamente é inútil querer escrever uma história à luz das atitudes mais recentes, procurar um fio condutor nesse domínio, uma indicação ou um sentido da história. Esta

\footnotetext{
${ }^{12}$ As noções de Durkheim e de Weber utilizadas em Os herdeiros integram a seleção do índex, o que também é bastante original na época.
} 
seria uma leitura intelectualista (ele sem dúvida diria escolástica) das obras literárias e das ciências sociais, pois, nelas são inevitavelmente encontradas inflexões, contradições, direções inexploradas ou abandonadas. Essa maneira de escrever ou de apresentar a história faz pensar que sempre há uma visada intencional na relação com a política, ao passo que, como todos sabem por experiência própria, os eventos muitas vezes podem nos constranger ao engajamento. A Guerra da Argélia foi um desses momentos em que ficou difícil não tomar posição, ainda mais quando se estava no local, como ilustram outros casos de pesquisadores em ciências sociais na época ${ }^{13}$.

Isso, no entanto, não é o essencial. As pesquisas de Pierre Bourdieu (e de sua equipe) ilustraram (e continuam ilustrando) essa dupla característica antiga da sociologia, a do desvelamento e da desnaturalização do social, carcaterística que se encontra também em Durkheim, por exemplo. Como sublinha Berger, a sociologia tem em seus princípios um projeto de desmistificação dos sistemas sociais que ela estuda (BERGER, 2006, p. 72-79). Nós não apreendemos o que as instituições dizem de si mesmas como fato consumado. Nós queremos, portanto, ver pessoalmente o que se esconde atrás da fachada, da vitrine oficial. Como sempre estudamos práticas, fenômenos que ultrapassam o quadro oficial destes, inevitavelmente desvelamos forças ocultas da ação. Uma das maneiras de fazê-lo é dizer que as instituições preenchem funções diferentes daqueles que lhes são oficialmente atribuídas. Assim, a escola não apenas instrui, mas contribui para a manutenção das desigualdades sociais, para a socialização dos indivíduos.

Todas as pesquisas empíricas de Pierre Bourdieu têm como ponto comum colocar as classes sociais no centro de coleta dos dados e da análise. Para cada um dos domínios aos quais ele se interessou (a arte, a educação, a cultura, a política), mostrou que o pertencimento social organizava as práticas. Sua grande enquete sobre o gosto, $A$ distinção. Crítica social do julgamento (1979), ilustra perfeitamente esta preocupação. O tema distinção como mecanismo de diferenciação social e o próprio termo (distinção) não eram, evidentemente, novos. Eles estão no centro do livro de Edmond Goblot, $A$ barreira e o nível (1925), que havia sido reeditado em 1967. Bourdieu retoma, portanto, esse tema, dando-Ihe uma consistência empírica maior e mais ampla e em domínios mais variados. Se houvesse um fio condutor na obra de Bourdieu, este seria

\footnotetext{
13 Em Bourdieu (2002) notar-se-á, aliás, a desproporção entre a parte dos textos reunidos no período anterior à 1980 e os que concernem o período seguinte. Ao menos podemos concluir que a publicação por Bourdieu de textos "engajados" em suportes de publicação não acadêmicos se tornam mais frequentes, o que não diz evidentemente nada sobre o engajamento anterior.
} 
incontestavelmente o que se deveria reter. Bourdieu quer mostrar nesta pesquisa que nossas práticas individuais em matéria de alimentação, vestuário, cultura e política formam um conjunto homogêneo definido pelo nosso pertencimento a uma ou outra classe social (ou fração de classe). Não há gosto pessoal, mas uma hierarquia social dos gostos definida pelo espaço das classes sociais. Sua análise se opõe, assim, à concepção, provavelmente corrente, de que o gosto é uma questão de escolha pessoal, de livre arbítrio, e que ele não seria, portanto, socialmente determinado. Nesse sentido, sua análise desvela uma estrutura que nós não suspeitávamos. Ao mesmo tempo, ela desnaturaliza nossa concepção sobre o gosto e, mais que isso, as práticas culturais. Além de uma percepção corrente e comum - "todos os gostos estão na natureza; os gostos e as cores não se discutem" -, Bourdieu nos mostra, como faz com frequência a sociologia, que eles são determinados pelo nosso pertencimento social (sexo, geração, habitat e, sobretudo, classe social).

Ao adotar uma análise em termos de classes sociais, as pesquisas sociológicas empíricas oscilam entre duas direções. Ou tentam caracterizar globalmente as relações de classes, na sequência das análises de Marx, a fim de extrair um ponto de vista geral sobre a sociedade organizada em torno desta noção: A escola capitalista na França (1971) de Christian Baudelot e Roger Establet estaria neste grupo; ou se propõem a estudar as características e os comportamentos de uma população empiricamente definida, partindo geralmente das categorias estatísticas do INSEE (o código das categorias socioprofissionais, por exemplo): o estudo de A. Chenu sobre Os empregados (2000) representa bem este conjunto de pesquisas. Nesse caso, elas se apoiam em estatísticas que são apresentadas como provas a suas análises. Certamente, as pesquisas empíricas podem combinar essas duas direções na tentativa de estabelecer uma correspondência entre o código das categorias socioprofissionais e uma análise em termos de classes sociais, um ponto de vista abstrato sobre as relações de dominação entre as classes; elas podem propor uma análise das relações de classes ao descrever os comportamentos típicos das principais classes sociais selecionadas. Os herdeiros assim como A distinção são uma tentativa para conciliar essas duas direções. Essas duas obras, a primeira publicada em 1964, a segunda em 1979, marcam um período em que predominaram duas características: 1) a supremacia da análise multivariada, baseada em enquetes por questionário e a análise secundária de dados; 2 ) e uma forma de estruturalismo, em que 
os sociólogos pretendiam levar o conjunto dos fenômenos que observavam a uma ordem estável e definida, organizada principalmente em torno de uma categoria (as classes sociais). O livro de Bourdieu e Passeron, Os herdeiros, preenche amplamente este objetivo e por isso se tornou emblemático desse período da sociologia francesa.

\section{Referências}

BAUDELOT, C.; BENOLIEL, R.; CUKROWICZ, H.; ESTABLET, R. Les étudiants, l'emploi et la crise. Paris: Éditions Maspero, 1981.

BAUDELOT, C.; ESTABLET, R. L'école capitaliste en France. Paris: Éditions Maspero, 1971. BERGER. P. Invitation à la sociologie. Paris: La Découverte, 2006.

BOUDON, R. L'inégalité des chances. Paris: Armand Colin, 1973.

BOURDIEU, P. Interventions (1961-2001). Science sociale et action politique. Marseille: Agone, 2002.

BOURDIEU, P. La distinction. Critique social du jugement. Paris: Seuil, 1979.

BOURDIEU, P. Méditations pascaliennes. Paris: Seuil, 1997.

BOURDIEU, P.; CHAMBOREDON, J.-C.; PASSERON, J.-C. Le métier de sociologue. Paris: Mouton/Bordas, 1968.

BOURDIEU, P.; DARBEL, A. Travail et travailleurs en Algérie. Paris: Mouton, 1963.

BOURDIEU, P.; PASSERON, J.-C. La reproduction. Eléments pour une théorie du système d'enseignement. Paris: Éditions de Minuit, 1970.

BOURDIEU, P.; SAYAD, A. Le déracinement. La crise de l'agriculture traditionnelle en Algérie. Paris: Minuit, 1964.

CHAPOULIE, J.-M.; KOURCHID, O.; ROBERT, J.-L.; SOHN, A.-M. (dir.). Sociologies et sociologues. La France des années 1960. Paris: L'Harmattan, 2005.

CONNEL, R.W. «Why is classical theory classical? », American Journal of Sociology, vol. 102, $\mathrm{n}^{\circ}$ 6, 1997, p. 1511-1557.

CROZIER, M. Le Phénomène bureaucratique. Paris: Seuil, 1964.

FORNEL, M.; PASSERON, J.-C. (dir.). L'Argumentation. Preuve et persuasion. Paris: Éd. de l'EHESS («Enquête » 2), 2002, 191 p.

GOBLOT, E. La barrière et le niveau, étude sociologique sur la bourgeoisie française

moderne. Paris: PUF, 1925. 
GRIGNON, C.; PASSERON, J.-C. Le savant et le populaire: misérabilisme et populisme en sociologie et en littérature. Paris: Seuil/Gallimard, École des hautes études, 1989.

LÉVI-STRAUSS, C. Anthropologie structurale. Paris: Plon, 1958.

LÉVI-STRAUSS, C. Tristes Tropiques. Paris: Plon, 1955.

MASSON, P. « La fabrication des Héritiers », Revue française de sociologie, vol. 42, $\mathrm{n}^{\circ} 3$, 2001, p. 477-507.

MASSON, P. « Premières réceptions et diffusions des Héritiers (1964-1973) », Revue d'histoire des sciences humaines, $n^{\circ} 13,2005$, p. 69-98.

MASSON, P. Faire de la sociologie. Les grandes enquêtes françaises depuis 1945. Paris: La Découverte, 2008.

MORIN, E. L'esprit du temps. Paris: Grasset, 1962.

PASSERON, J.-C. « La signification des théories de la reproduction socio-culturelle ». Revue internationale des sciences sociales, $n^{0} 110,1986$, p. 127-138; p. 619-626; p. 665-675.

PASSERON, J.-C. La photographie parmi le personnel des usines Renault. Paris: CSE, ronéotype, 1962.

PASSERON, J.-C. Le raisonnement sociologique. L'espace non poppérien du raisonnement naturel. Paris: Nathan, 1991.

PROST, A. Éducation, société et politiques. Une histoire de l'enseignement en France de 1945 à nos jours. Paris: Seuil, 1992.

WALLERSTEIN, I. «L'héritage de la sociologie, la promesse de la science sociale ». Sociétés contemporaines, $n^{\circ}$ 33-34, 1999, p. 159-194.

Recebido em: 10/10/2013 Aprovado em: 28/02/2014

Universidade do Estado de Santa Catarina - UDESC Programa de Pós-Graduação em Educação - PPGE Revista Linhas

Volume 15 - Número 29 - Ano 2014 revistalinhas@gmail.com 